Research Paper

\title{
Hollow-Bone-Graft Dynamic Hip Screw Can Fix and Promote Bone Union after Femoral Neck Fracture: an Experimental Research
}

\author{
Jia-zuo SHEN, Jian-fei YAO, Da-sheng LIN, Ke-jian LIAN ${ }^{\bowtie}$, Zhen-qi DING, Bin LIN, Zhi-min GUO, \\ Ming-hua ZHANG, Qiang LI, Lin LI, Peng QI
}

Department of Orthopaedic Surgery, the Affiliated Dongnan Hospital of Xiamen University, Orthopaedic Trauma Center of the 175th Hospital of PLA, Zhangzhou, Fujian, 363000, PR China.

$\triangle$ Corresponding author: Ke-jian LIAN, MD. 268 Zhang-Hua Road, Zhangzhou, 363000, Fujian Province, PR China. Tel: +86-13063196989; Fax: +86-596-2931538; E-mail: 24520091152983@stu.xmu.edu.cn \& shenjiazuo09@163.com.

( ) Ivyspring International Publisher. This is an open-access article distributed under the terms of the Creative Commons License (http://creativecommons.org/ licenses/by-nc-nd/3.0/). Reproduction is permitted for personal, noncommercial use, provided that the article is in whole, unmodified, and properly cited.

Received: 2012.05.08; Accepted: 2012.08.05; Published: 2012.11.22

\begin{abstract}
Background: Delayed bone union, nonunion or osteonecrosis often occur after femoral neck fractures in young adults. Secondary bone healing requires strong internal fixation, intramedullary pressure reduction and early functional exercise.

Objective: To compare bone healing of femoral neck fractures treated with hollow-bone-graft dynamic hip screws (Hb-DHS) and standard dynamic hip screws (DHS) in an animal model.

Design: Testing of specifically designed fixation devices in a pig animal model.

Interventions/Methods: We designed Hb-DHS and DHS devices appropriate to the femoral neck and head of exDerimental animals and used them in eight pigs (4-month-old, male or female, $30-40 \mathrm{~kg} /$ each). Under anesthesia, we induced medium neck type, Garden III type femoral neck fractures in each pig with fracture gaps of $0.5 \mathrm{~mm}$ and then fixed each left femur with $\mathrm{Hb}-\mathrm{DHS}$ and each right femur with DHS. We assessed the animals radiographically and by postmortem visual appraisal of evidence of bone healing 8 and 16 weeks postoperatively.

Results: There were significant differences in radiographic and general findings between the $\mathrm{Hb}-\mathrm{DHS}$ and DHS groups at weeks 8 and 16 postoperatively. We found statistically significant differences between the Hb-DHS and DHS groups in bone healing scores, trabecular bone volume percentage and bone mineral density as assessed on plain radiographs and computed tomography images $(P<0.05)$. There were also significant differences between the $\mathrm{Hb}-\mathrm{DHS}$ and DHS groups in postmortem visually assessed indicators of bone healing at both 8 and 16 weeks postoperatively.

Conclusions: The Hb-DHS device promotes femoral neck bone union, stimulates trabecular bone formation, increases BMD and has advantages over DHS for internal fixation of femoral neck fractures. This animal experiment will contribute to developing optimal treatment for femoral neck fractures in young adults.
\end{abstract}

Key words: Animal Research; Bone Graft; Dynamic Hip Screw; Femoral Neck Fracture; Hollow Screw; Pig; Young Adult.

\section{Introduction}

The main causes of femoral neck fractures in young adults are high energy injuries ${ }^{[1]}$ sustained in traffic accidents, falls and so on. Since Smith-Petersen introduced the use of three wing screws for internal 
fixation, over 100 other internal fixation devices have been developed. The most recent therapeutic methods include closed internal fixation and open reduction with internal fixation. Orthopedists tend to select cannulated screw for closed internal fixation and standard DHS for open reduction with internal fixation materials ${ }^{[2]}$; however, these devices have many adverse consequences, such as screw cut out ${ }^{[3]}$, delayed bone healing, bony nonunion (about 15\%) and avascular necrosis $(20 \%-30 \%)$. So far, because there have been no significant breakthroughs in therapeutic approaches, these fractures have been considered one of the unresolved issues in orthopaedics.

The main purpose of this study was to design a new type of internal fixation device that fixes femoral neck fractures strongly and uses autogenous bone grafts to reduce the incidence of delayed bone union, nonunion and osteonecrosis.

\section{Materials and Methods}

\section{Construction of Screws}

In collaboration with Xiamen Double Engine
Medical Material (Xiamen, China), we designed the $\mathrm{Hb}$-DHS and obtained a patent for it (patent number: 201110146729.6). This device is made of titanium alloy and divided into head, middle and end sections. The head section, which is threaded and has some holes in it, is used to fix the femoral head; autogenous bone graft is inserted into the middle section, which has a flabellum-like-cavity; and the end section is inserted into a $135^{\circ}$ angle plate.

\section{Experimental Animals and Grouping}

All experimental animal procedures were approved and in accordance with the guidelines of the Institutional Animal Care and Use Committee of the authors' institution. We selected eight 4-month-old pigs (either male and female, weighing 30-40 kg each) and maintained them in our experimental animal center for 1 week to acclimate to the diet, water, housing, and 12/12 hours light/dark cycle. We then performed three-dimensional CT scans on these animals and made hip models to assist the surgical procedure.

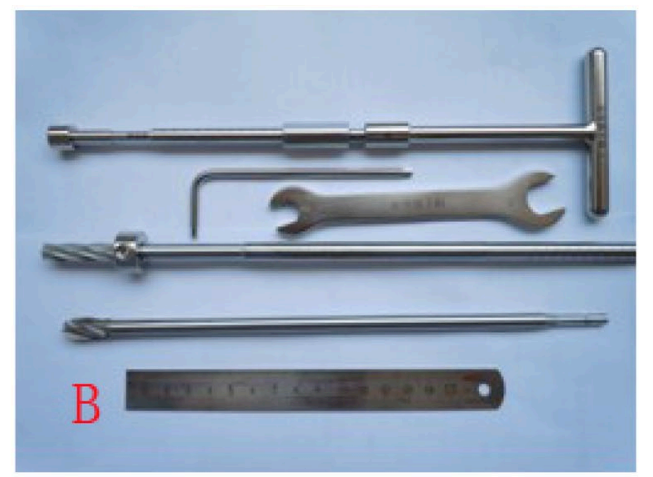

Figure I. A showed the Hb-DHS and the DHS, Hb-DHS was divided into three sections: head(length: I cm; external diameter:0.8cm, inner diameter:0.4cm), middle(length: $1 \mathrm{~cm}$; external diameter:0.8cm, inner diameter:0.4cm; 4 holes), end(length: $1.5 \mathrm{~cm}$; external diameter: $0.6 \mathrm{~cm}$, inner diameter: $0.2 \mathrm{~cm})$; B showed the autogeneous-bone grafting instrument and DHS drills.
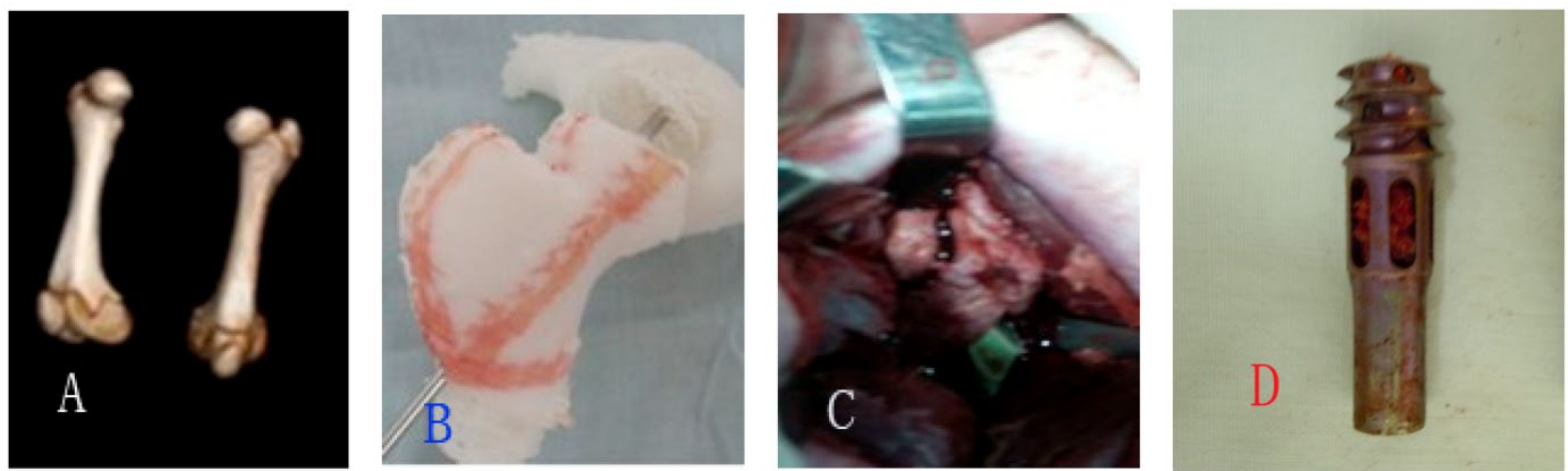

Figure 2. A showed three-dimensional CT scan of pigs' femurs; B showed femoral models of pigs; C showed fractured gap intraoperatively; D showed autogeneous bones were grafted into $\mathrm{Hb}-\mathrm{DHS}$. 


\section{Surgical Procedure and Postoperative Care}

The authors performed all surgeries under basic anesthesia (xylazine $0.1 \mathrm{~mL} / \mathrm{kg}$ compounded with ketamine $0.1 \mathrm{~mL} / \mathrm{kg} \mathrm{im}$ ).We used the classical Watson-Jones approach, peeled back the connective and muscular tissue, exposed the greater trochanter and hip joint capsule and opened the hip joint capsule to expose the femoral neck. Then we severed the femoral neck with a chisel to create a model fracture (medium neck type, Garden III type, fracture gap $0.5 \mathrm{~mm}$ ). Next, we temporarily fixed the head and the neck with a $1.5 \mathrm{~mm}$ diameter Kirschner wire and took X-rays. Then we implanted a bone graft from the ipsilateral ilial tuberosity (without any complications) into the flabellum-like cavity of a Hb-DHS and fixed the left femurs with a Hb-DHS and the right femurs with a DHS. Postoperatively, all experimental pigs received routine care and im penicillin (800 000 units) for 7 days to prevent incision infection. They were housed separately for 5 days, and then in groups.

\section{Radiographic Assessment}

In weeks 8 and 16 postoperatively, we took plain X-rays and performed CT scans of both hips and used them to assess bone healing according to the Lane-Sandhu score ${ }^{[4]}$ (Table 1), percentage of trabecular bone volume $(\mathrm{Vp})$ and bone mineral density (BMD). The $\mathrm{Vp}$ was calculated by the formula $\mathrm{Vt} /(\mathrm{Vt}$ $+\mathrm{Vm})$, where $\mathrm{Vt}$ is the value within the femoral neck and Vm that outside the femoral neck. The BMD was calculated by automatic analytical software based on the CT scan. The plain X-ray films were taken with equipment at a voltage of $55 \mathrm{kV}$, course of 1 second, current of $100 \mathrm{~mA}$, and a distance between ball tube and sample of $80 \mathrm{~cm}$. The CT scanner was a Siemens Somatom Sensation 64 CT 2007 (Erlangen, Germany) with a voltage of $120 \mathrm{kV}$, course of 1 second, current of $180 \mathrm{~mA}$, collimation of $0.6 \mathrm{~mm} \times 64$, tomoscan thickness of $3 \mathrm{~mm}$, tomoscan distance of $3 \mathrm{~mm}$, pitch of 0.9 , restitution thickness of $0.75 \mathrm{~mm}$, and spacer of 0.75 $\mathrm{mm}$.

Table I. Lane-Sandhu Score.

\begin{tabular}{ll}
\hline Score & Callus Formation and Fracture Line \\
\hline 0 & no callus formation and clear fracture line \\
1 & $25 \%$ callus formation and relatively clear fracture line \\
2 & $50 \%$ callus formation and obscure fracture line \\
3 & $75 \%$ callus formation and almost invisible fracture line \\
4 & $100 \%$ callus formation and invisible fracture line \\
\hline Because there is no callus formation in secondary bone healing of femoral \\
neck fractures, we used the visibility of the fracture line to evaluate differ- \\
ences in bone healing.
\end{tabular}

\section{Visual Assessment of Evidence of Bone Heal- ing}

In the 8th and 16th postoperative weeks, after performing X-ray and CT examinations, we bled the animals to death under basic anesthesia (xylazine 0.1 $\mathrm{mL} / \mathrm{kg}$ compounded with ketamine $0.1 \mathrm{~mL} / \mathrm{kg}$ im) and then visually assessed the blood supply of the femoral head, the state of the grafted bone in the flabellum-like cavity of the $\mathrm{Hb}$-DHS and trabecular bone formation.

\section{Statistical Analysis}

We analyzed the data with SPSS 16.0 statistical software and used the Wilcoxon rank sum test to analyze quantitative data that did not have normal distribution and homoscedasticity. We defined $P<0.05$ as statistically significant.

\section{Results}

No pigs had postoperative complications and all were able to walk on the 3rd postoperative day and had stable fixation of their femurs at 8 and 16 weeks. At 8 and 16 weeks postoperatively, we assessed the experimental animals by X-rays, CT scans and postmortem visual appraisal of evidence of bone healing (Figures 3, 4, 5).

\section{Radiographic Assessment}

Eight weeks postoperatively, bone healing according to the Lane-Sandhu score was better in the $\mathrm{Hb}$-DHS than in the DHS group, this difference being statistically significant $(Z$ test $-2.530, P<0.05)$ (Tables 2 and 3$)$. The $V p$ and BMD were also significantly better in the Hb-DHS than in the DHS group ( $\mathrm{Z}$ test -2.337 for $\mathrm{Vp},-2.291$ for $\mathrm{BMD}$ on the tension side and -2.309 for BMD on the pressure side, $P<0.05)$. Sixteen weeks postoperatively, bone healing according to the Lane-Sandhu score was still significantly better in the $\mathrm{Hb}$-DHS than the DHS group ( $\mathrm{Z}$ test $-2.247, P<0.05$ ). The Vp and BMD were also significantly better in the $\mathrm{Hb}$-DHS than the DHS group ( $\mathrm{Z}$ test -2.336 for $\mathrm{Vp}$, -2.247 for BMD on the tension side, -2.309 for BMD on the pressure side, $P<0.05$ ) (Tables 2 and 3 ).

\section{Visual Assessment of Evidence of Bone Heal- ing}

Eight weeks postoperatively, the blood supply to the femoral head was better in the Hb-DHS than the DHS group (kermesinus in the $\mathrm{Hb}$-DHS versus pale in the DHS group, Figure 5A) and the grafted bone in the flabellum-like cavity of the Hb-DHS had survived and merged with surrounding bone tissue with abundant trabecular bone formation (Figure 5B). Sixteen weeks postoperatively, the blood supply to the 
femoral head was still better in the $\mathrm{Hb}$-DHS than the DHS group and also better than that in the Hb-DHS group at week 8 (pink in the Hb-DHS at week 16 versus kermesinus in the DHS group at week 16, kermesinus in the $\mathrm{Hb}$-DHS group at week 8 , Figure
5A/C). The grafted bone in the flabellum-like cavity of the Hb-DHS had survived and merged with surrounding bone tissues and a mass of trabecular bone had formed; there was a significant improvement over the findings in week 8 (Figure 5B/D).

Table 2. Results of Lane-Sandhu Score in Hb-DHS Group and DHS Group.

\begin{tabular}{llllll}
\hline Weeks & Parameters & Hb-DHS Group & DHS Group & Z & P \\
\hline 8 weeks & M/S & $6.50 / 26.00$ & $2.50 / 10.00$ & -2.530 & $<0.05$ \\
16 weeks & M/S & $6.38 / 25.50$ & $2.62 / 10.50$ & -2.247 & $<0.05$ \\
\hline
\end{tabular}

Defined $\mathrm{P}<0.05$ to be statistically significant difference; M/S demonstrated Mean Rank/ Sum of Ranks; $Z$ demonstrated $Z$ test; $P$ demonstrated exact.sig.

Table 3. Results of $V_{p}$ and BMD in Hb-DHS Group and DHS Group.

\begin{tabular}{|c|c|c|c|c|c|c|}
\hline Weeks & Parameters & & Hb-DHS Group & DHS Group & Z & $\mathrm{P}$ \\
\hline \multirow[t]{3}{*}{8 weeks } & & $\mathrm{pp}$ & $6.50 / 26.00$ & $2.50 / 10.00$ & -2.337 & $<0.05$ \\
\hline & $\mathrm{BMD}(\mathrm{M} / \mathrm{S})$ & Tension Side & $6.50 / 26.00$ & $2.50 / 10.00$ & -2.291 & $<0.05$ \\
\hline & & Pressure Side & $6.50 / 26.00$ & $2.50 / 10.00$ & -2.309 & $<0.05$ \\
\hline \multirow[t]{3}{*}{16 weeks } & & $\mathrm{p}$ & $6.50 / 26.00$ & $2.50 / 10.00$ & -2.336 & $<0.05$ \\
\hline & $\mathrm{BMD}(\mathrm{M} / \mathrm{S})$ & Tension Side & $6.50 / 26.00$ & $2.50 / 10.00$ & -2.247 & $<0.05$ \\
\hline & & Pressure Side & $6.50 / 26.00$ & $2.50 / 10.00$ & -2.309 & $<0.05$ \\
\hline
\end{tabular}

Defined $\mathrm{P}<0.05$ to be statistically significant difference; $\mathrm{Vp}$ demonstrated trabecular bone volume percentage; BMD demonstrated bone mineral density; $\mathrm{M} / \mathrm{S}$ demonstrated Mean Rank/ Sum of Ranks; Z demonstrated Z test; $P$ demonstrated exact.sig.
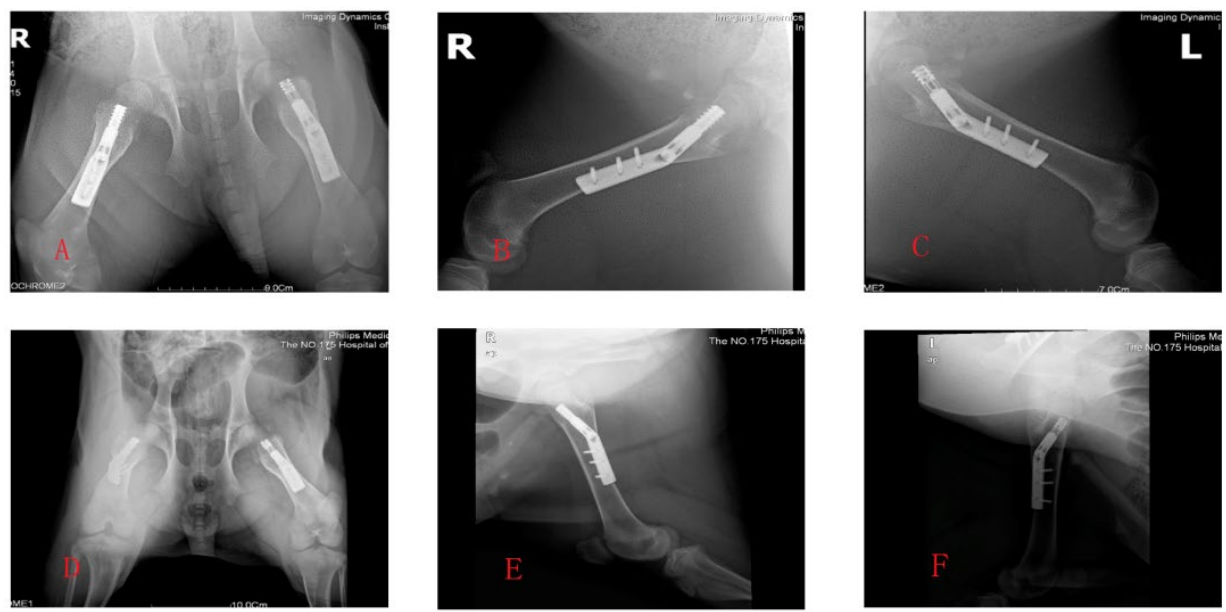

Figure 3. A,B,C showed the X-ray photographs at week 8 postoperatively; D,E,F showed the X-ray photographs at week 16 postoperatively. 

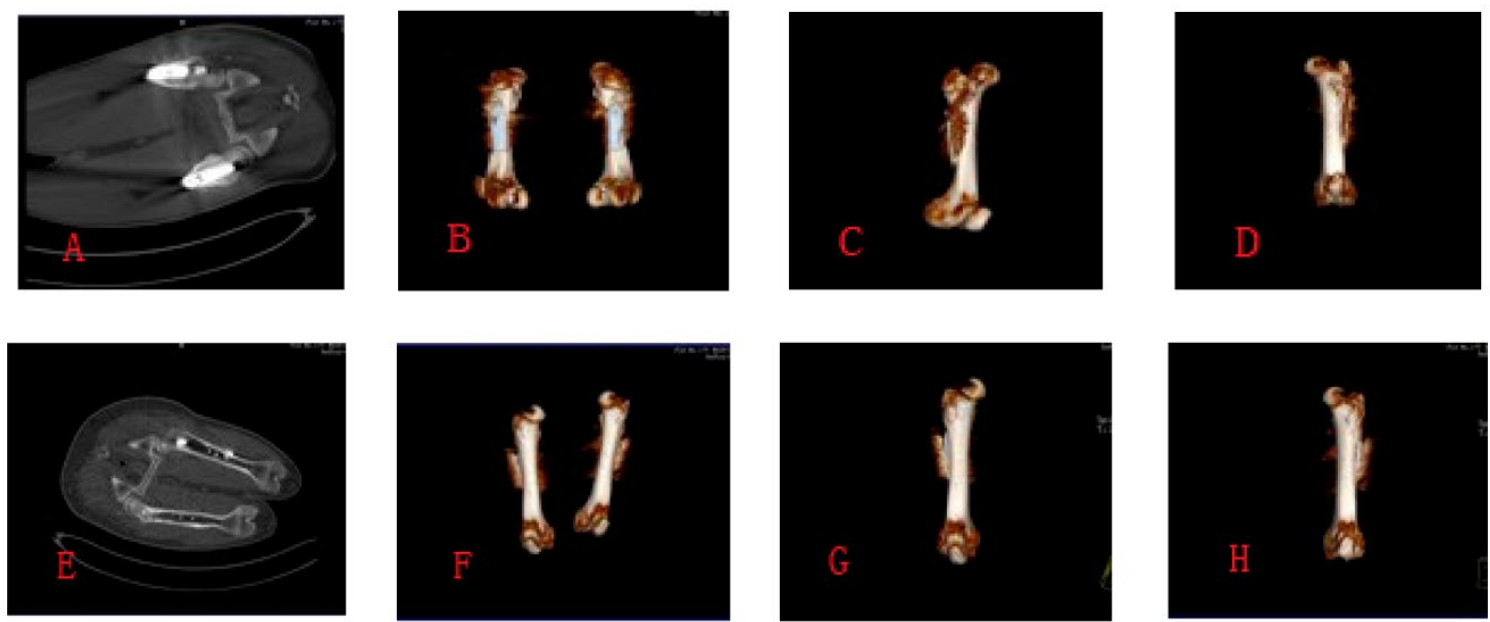

Figure 4. A,B,C,D showed the CT scan photographs at week 8 postoperatively; E,F,G,H showed the CT scan photographs at week 16 postoperatively.
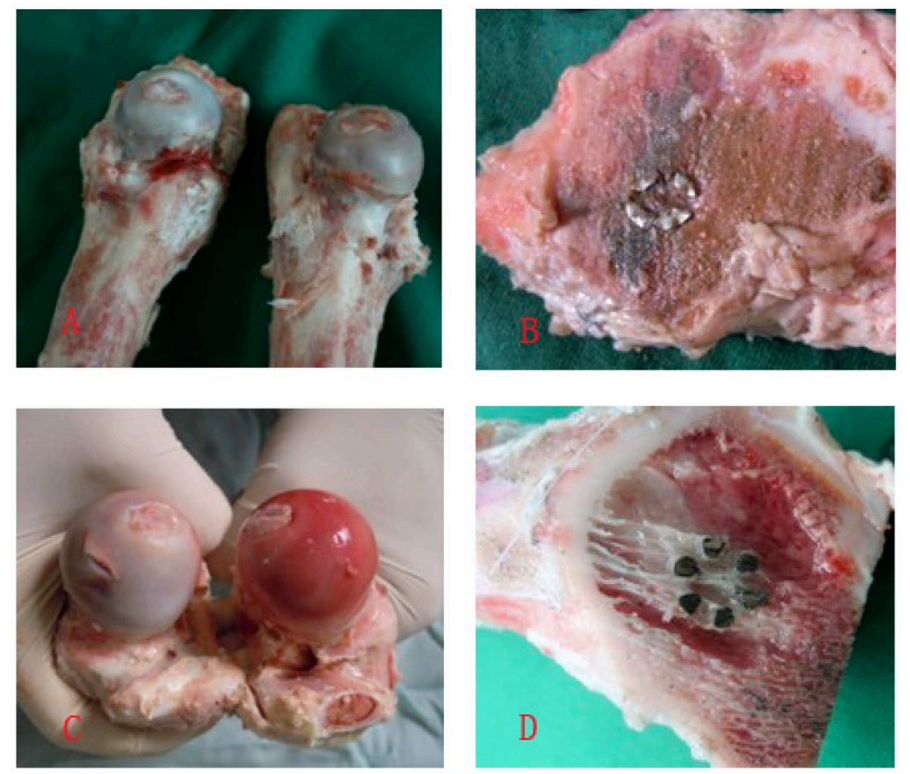

Figure 5. A showed the general specimens at week 8, kermesinus in Hb-DHS group(right), pale in DHS group(left); B showed transection of femoral neck and could see the flabellum-like-hole of $\mathrm{Hb}$-DHS and plenty of trabecular bone formation at week 8; $\mathrm{C}$ showed the general specimens at week 16, pink in Hb-DHS group(right), kermesinus in DHS group(left); D showed transection of femoral neck and could see the flabellum-like-hole of $\mathrm{Hb}-\mathrm{DHS}$ and a mass of trabecular bone formation at week 16.

\section{Discussion}

The main causes of femoral neck fractures in young adults are high energy injuries sustained in traffic accidents, falls and so on ${ }^{[5]}$. Various factors, including specific characteristics of the anatomical structure of the femoral neck, may contribute to delayed bone union, nonunion (about 15\%) and femoral head necrosis $(20-30 \%)$. These factors include delays in hospitalization, unconsciousness, open versus closed reduction and internal fixation, quality of internal fixation, lack of suitable equipment, femoral neck bone quality, fracture type, creeping substitution of bone, increases in capsular and intramedullary pressure, and reduction in local blood supply ${ }^{[5-7]}$.

The main therapeutic principles in the management of femoral neck fractures are early, accurate restoration of the femoral neck and head, firm internal fixation, reconstruction of blood supply, rehabilitation exercises, and reduction of complications ${ }^{[8]}$. Surgical methods include open or closed reduction with internal fixation ${ }^{[9-11]}$. Abundant internal fixation devices are available, including single screw, several screws, slide plates, DHS, absorbed material, bone grafts, and 
osteotomy $^{[12-19]}$; these have various advantages and disadvantages. Until now, there has been no optimal internal fixation device for promoting femoral neck bone union.

In consideration of the above, our research group designed a new screw and collaborated with Xiamen Double Engine Medical Material to produce it. The device is an improvement of DHS; we named it $\mathrm{Hb}$-DHS. The head section of the Hb-DHS is threaded, has some holes and is used to fix the femoral head, possibly with less capsular and intramedullary pressure than there is with the DHS. The middle section of the $\mathrm{Hb}$-DHS has a flabellum-like cavity into which iliac autogenous bone graft is inserted to reduce bone necrosis, promote creeping substitution of bone and, to some extent, augment bone trabecular volume and $\mathrm{BMD}$. The end section of the $\mathrm{Hb}-\mathrm{DHS}$ inserts into a $135^{\circ}$ angle plate.

Compared with the Hb-DHS, the DHS probably does not reduce capsular and intramedullary pressure, does not provide for iliac autogenous bone graft and has various complications including coxa vara, screw cut out or loosening, and plate rupture ${ }^{[20,21]}$, which can endanger the femoral head, reduce bone trabecular formation, exacerbate bone ischemia and result in bone necrosis. The Hb-DHS may also have some complications, including loosening of the screw thread, lock nail and angle plate, screw cut out, and plate rupture. However, the $\mathrm{Hb}-\mathrm{DHS}$ is unique in having holes on the screw thread in the head and a flabellum-like cavity in the middle section that might somewhat reduce capsular and intramedullary pressure. The autogenous bone graft in the flabellum-like cavity may promote trabecular bone formation, increase bone mineral density and creeping substitution, and decrease the healing time. However, once bone healing has occurred, Hb-DHS may have some drawbacks in that it would be more difficult to remove than other internal fixation devices and may cause electrolytic or anaphylactic reactions.

We believe that the $\mathrm{Hb}$-DHS could be used not only for autogenous bone graft but also for injection of drugs, growth factor, mesenchymal stem cells and so on to promote fracture healing ${ }^{[22-25]}$. In addition, in the future it may be possible to substitute absorbable materials such as porous tantalum for the titanium alloy. Therefore, we predict that, once $\mathrm{Hb}$-DHS is widely used clinically, it will become the treatment of choice for femoral neck fracture in young adults.

\section{Conclusion}

In this experimental study, the Hb-DHS device was superior to the DHS for fixing femoral head and neck fractures, as evidenced by X-ray film and CT assessment and visual assessment of postmortem specimens, and may therefore come to play an important role in the management of femoral neck fractures in young adults.

\section{Authors' contributions}

SHEN Jia-zuo and LIAN Ke-jian contributed equally to the work. SHEN Jia-zuo wrote the article. The foundation was supported by science and technology fund from Nanjing Military Region (No. 10MA073). All authors read and approved the final manuscript.

\section{Conflict of Interest}

The authors have declared that no conflict of interest exists.

\section{Abbreviations}

Hb-DHS: Hollow-Bone-Graft Dynamic Hip Screw; DHS: Dynamic Hip Screw; BMD: Bone Mineral Density; Vp: Volume Percentage;

\section{References}

[1] Shrader MW, Jacofsky DJ, Stans AA, Shaughnessy WJ, Haidukewych GJ. Femoral neck fractures in pediatric patients: 30 years experience at a level 1trauma center. Clin Orthop Relat Res. 2007. 454: 169-73.

[2] Roshan A, Ram S. Early return to function in young adults with neglected femoral neck fractures. Clin Orthop Relat Res. 2006. 447: 152-7.

[3] Davidovitch RI, Jordan CJ, Egol KA, Vrahas MS. Challenges in the treatment of femoral neck fractures in the nonelderly adult. J Trauma. 2010. 68(1): 236-42.

[4] Lane JM, Sandhu HS. Current approaches to experimental bone grafting. Orthop Clin North Am. 1987. 18(2): 213-25.

[5] Heetveld MJ, Raaymakers EL, Luitse JS, Nijhof M, Gouma DJ. Femoral neck fractures: can physiologic status determine treatment choice. Clin Orthop Relat Res. 2007. 461: 203-12.

[6] Bowlus RA, Armbrust LJ, Biller DS, Hoskinson JJ, Kuroki K, Mosier DA. Magnetic resonance imaging of the femoral head of normal dogs and dogs with avascular necrosis. Vet Radiol Ultrasound. 2008. 49(1): 7-12.

[7] Kang PD, Shen B, Yang J, Dang HS, Pei FX. [Platelet and endothelial cell-derived microparticles in steroid-induced osteonecrosis of the femoral head of rabbit model]. Zhonghua Yi Xue Za Zhi. 2007. 87(29): 2045-9.

[8] Ma HZ, Zeng BF, Li XL. Upregulation of VEGF in subchondral bone of necrotic femoral heads in rabbits with use of extracorporeal shock waves. Calcif Tissue Int. 2007. 81(2): 124-31.

[9] Windolf M, Braunstein V, Dutoit C, Schwieger K. Is a helical shaped implant a superior alternative to the Dynamic Hip Screw for unstable femoral neck fractures? A biomechanical investigation. Clin Biomech (Bristol, Avon). 2009. 24(1): 59-64.

[10] Majernicek M, Dungl P, Kolman J, Malkus T, Vaculik J. [Osteosynthesis of intracapsular femoral neck fractures by dynamic hip screw (DHS) fixation]. Acta Chir Orthop Traumatol Cech. 2009. 76(4): 319-25.

[11] Parker MJ, Stedtfeld HW. Internal fixation of intracapsular hip fractures with a dynamic locking plate: initial experience and results for 83 patients treated with a new implant. Injury. 2010. 41(4): 348-51.

[12] Lu H, Ni W, Gao S. [Biomechanical research of ideal compression screw for treatment of femoral neck fracture]. Zhongguo Xiu Fu Chong Jian Wai Ke Za Zhi. 2009. 23(5): 566-9.

[13] Paech A, Wilde E, Schulz AP, et al. Biopolymer augmentation of the lag screw in the treatment of femoral neck fractures--a biomechanical in-vitro study. Eur J Med Res. 2010. 15(4): 174-9.

[14] Jukkala-Partio K, Partio EK, Helevirta P, Pohjonen T, Tormala P, Rokkanen P. Treatment of subcapital femoral neck fractures with bioabsorbable or metallic screw fixation. A preliminary report. Ann Chir Gynaecol. 2000. 89(1): 45-52. 
[15] Kakar S, Little D, Einhorn TA. Can we improve fixation and outcomes in the treatment of femoral neck fractures? The use of pharmaceuticals. J Orthop Trauma. 2009. 23(6): 413-21.

[16] Eid A. Valgus osteotomy for delayed presentation of femoral neck fractures Pauwels Grade III. J Orthop Trauma. 2010. 24(2): 115-9.

[17] Magu NK, Rohilla R, Singh R, Tater R. Modified Pauwels' intertrochanteric osteotomy in neglected femoral neck fracture. Clin Orthop Relat Res. 2009. 467(4): 1064-73.

[18] Blomfeldt R, Tornkvist H, Ponzer S, Soderqvist A, Tidermark J. Displaced femoral neck fracture: comparison of primary total hip replacement with secondary replacement after failed internal fixation: a 2-year follow-up of 84 patients. Acta Orthop. 2006. 77(4): 638-43.

[19] Frihagen F, Figved W, Madsen JE, Lofthus CM, Stoen RO, Nordsletten L. [The treatment of femoral neck fractures]. Tidsskr Nor Laegeforen. 2010. 130(16): 1614-7.

[20] Heetveld MJ, Raaymakers EL, Luitse JS, Nijhof M, Gouma DJ. Femoral neck fractures: can physiologic status determine treatment choice. Clin Orthop Relat Res. 2007. 461: 203-12.

[21] Parker MJ, Raghavan R, Gurusamy K. Incidence of fracture-healing complications after femoral neck fractures. Clin Orthop Relat Res. 2007. 458: $175-9$.

[22] Stogiannidis I, Puolakka T, Pajamaki J, Moilanen T, Konttinen YT. Whole-mount specimens in the analysis of en bloc samples obtained from revisions of resurfacing hip implants. A report of 4 early failures. Acta Orthop. 2010. 81(3): 324-30.

[23] Ahn J, Man LX, Park S, Sodl JF, Esterhai JL. Systematic review of cemented and uncemented hemiarthroplasty outcomes for femoral neck fractures. Clin Orthop Relat Res. 2008. 466(10): 2513-8.

[24] Norrish AR, Rao J, Parker MJ. Prosthesis survivorship and clinical outcome of the Austin Moore hemiarthroplasty: An 8-year mean follow-up of a consecutive series of 500 patients. Injury. 2006. 37(8): 734-9.

[25] Raaymakers EL. Fractures of the femoral neck: a review and personal statement. Acta Chir Orthop Traumatol Cech. 2006. 73(1): 45-59. 